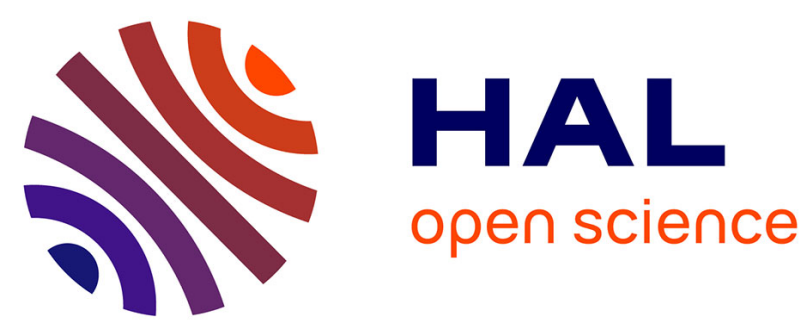

\title{
Does visual attention span relate to eye movements during reading and copying?
}

Marie-Line Bosse, Sonia Kandel, Chloé Prado, Sylviane Valdois

\section{To cite this version:}

Marie-Line Bosse, Sonia Kandel, Chloé Prado, Sylviane Valdois. Does visual attention span relate to eye movements during reading and copying?. International Journal of Behavioral Development, 2013, pp.DOI: $10.1177 / 0165025413509046$. 10.1177/0165025413509046 . hal-00945205

\section{HAL Id: hal-00945205 \\ https://hal.science/hal-00945205}

Submitted on 20 Feb 2014

HAL is a multi-disciplinary open access archive for the deposit and dissemination of scientific research documents, whether they are published or not. The documents may come from teaching and research institutions in France or abroad, or from public or private research centers.
L'archive ouverte pluridisciplinaire $\mathbf{H A L}$, est destinée au dépôt et à la diffusion de documents scientifiques de niveau recherche, publiés ou non, émanant des établissements d'enseignement et de recherche français ou étrangers, des laboratoires publics ou privés. 
Does visual attention span relate to eye movements during reading and copying?

\author{
Marie-Line Bosse (1) \\ Sonia Kandel $(1,2,3)$ \\ Chloe’ Prado (4) \\ and \\ Sylviane Valdois $(1,5)$
}

(1) Universite' Grenoble Alpes, LPNC, France

(2) Institut Universitaire de France, France

(3) Universite' Grenoble Alpes, GIPSA-LAB, France

(4) Centre Hospitalier Universitaire, Grenoble, France

(5) CNRS, LPNC UMR 5105, Grenoble, France

Corresponding author : Marie-line.bosse@upmf-grenoble.fr

Université Pierre Mendès France, Laboratoire de Psychologie et Neurocognition (CNRS

UMR 5105), B.P. 47 - BSHM. 38040 Grenoble Cedex 09, France. 


\begin{abstract}
This research investigated whether text reading and copying involve visual attention processing skills. Children in grades 3 and 5 read and copied the same text. We measured eye movements while reading and the number of gaze lifts (GL) during copying. The children were also administered letter report tasks that constitute an estimation of the number of letters that are processed simultaneously. The tasks were designed to assess visual attention span abilities (VA). The results for both grades revealed that the children who reported more letters, i.e., processed more consonants in parallel, produced fewer rightward fixations during text reading suggesting they could process more letters at each fixation. They also copied more letters per gaze lift from the same text. Furthermore, a regression analysis showed that VA span predicted variations in copying independently of the influence of reading skills. The findings support a role of VA span abilities in the early extraction of orthographic information, for both reading and copying tasks.
\end{abstract}

Key words: copying, reading, gaze lifts, eye-movements, visual attention span

Running head: The VA span in reading and copying processes 


\section{Introduction}

Children spend a great part of their school time in processing letter strings during reading and copying tasks. In both tasks there is an initial visual processing operation that results in the identification of the letter components. Studies on reading processes have shown that reading performance depends on phonological skills, of course, but also on visual attention ability. This refers to the simultaneous processing -in a single fixation- of several elements of a string (Ans, Carbonnel, \& Valdois, 1998; Valdois, Bosse, \& Tainturier, 2004). It is known as the visual-attention (VA) span. The VA span increases with reading expertise and contributes significantly to word (or pseudo-word) reading at all grades (Bosse \& Valdois, 2009). The aim of the present study is to examine the relationship between the VA span and the initial visual processing involved in reading and copying.

VA span abilities can be estimated by global and partial report tasks (Bosse, Tainturier, \& Valdois, 2007). In the global report task unreadable strings of consonants like "R S T D H" are presented for a very short time. The child's task is to recall the consonants that he/she remembers. The reason for presenting only consonants is to avoid the involvement of higher order reading processes such as grapheme complexity knowledge or orthographic lexical knowledge. None of the letter clusters in the consonant strings corresponded to complex graphemes in French (e.g., TH or GN) and none of the five consonants matched the skeleton of a real word (e.g., FLMBR for "FLAMBER"). The performance in this task does not reflect a verbal short-term memory load (Lassus-Sangosse, N'Guyen-Morel, \& Valdois, 2008) and is not affected by concurrent articulation (Valdois, Lassus-Sangosse, \& Lobier, 2012b) suggesting that it is not modulated by online verbal encoding skills. However, as these tasks use verbal stimuli and need a verbal response, it has been argued that they do not measure visual attention processing but verbal phonological code mapping (e.g., Ziegler, PechGeorgel, Dufau, \& Grainger, 2010). To rule out this possibility, the same kind of task was 
conducted using verbal and non-verbal material (Lobier, Zoubrinetzky, \& Valdois, 2012). The results revealed that dyslexic children with a VA span deficit performed poorly irrespective of stimulus material. Their disorder was therefore visual rather than verbal. Moreover, studies on normal reading children also showed that partial and global report tasks did not correlate with verbal abilities such as phonological awareness (Bosse \& Valdois, 2009). The report tasks could thus be considered as a tool to evaluate the child's ability to extract parallel visual information from the input string (see Lobier et al., 2012 and Valdois, Lassus-Sangosse, \& Lobier, 2012a, for extensive discussions on this controversy).

Since the visual attention span reflects the amount of orthographic information that can be extracted for further processing during the early stages of the reading process, we expected to observe a link between VA span abilities and eye movement measures that relate to orthographic information extraction during text reading. Data from a developmental dyslexia investigation indicated that dyslexics with a small VA span produce rightward fixations more frequently than normal reading children (Prado, Dubois, \& Valdois, 2007). The first objective of the present study was to examine whether the specific relationship between VA span abilities and rightward fixations during text reading is also observed in groups of typically developing children varying in reading expertise.

Since the VA span is related to the early processes involved in letter identification, it should be involved not only in reading but also in copying tasks. Although children frequently copy texts in everyday school life, research investigating the underlying mechanisms involved in this kind of task is very scarce. Studies on expert copying performance, using both eye and pen analyses, showed that adults could simultaneously write a word and process visually the following word to copy. Moreover, this anticipation phenomenon seems to rely on the orthographic characteristics of the target words (e.g., Lambert, Alamargot, Larocque, \& Caporossi, 2011). For children, writing and visual word processing requires considerable 
cognitive resources, so they alternate the two kind of processing during copying. Most studies investigating child copying abilities used gaze lifts (GL hereafter) as a measure of visual word processing. The location of a gaze lift within the word was considered as an indicator of sublexical segmentation (Humblot, Fayol, \& Lonchamp, 1994; Rieben \& Saada-Robert, 1991; Kandel \& Valdois, 2006a, 2006b). The rationale was that when the child does not have enough orthographic information on the spelling of the word, he/she writes the first letters and then produces a gaze lift to extract more information on the spelling of the remaining part of the letter string. In Kandel and Valdois (2006a) for instance, French children copied bisyllabic words and pseudo-words. The results revealed that the children in grades 1 and 2 lifted their gaze mostly at the word's syllable boundary. In contrast, the children in grades 3, 4 and 5 copied most of the items without producing gaze lifts. The authors concluded that at the beginning of the acquisition period the children could not extract enough orthographic information in a single visual fixation so they had to segment the letter string into chunks. These chunks are linguistically oriented, since they are systematically syllables. In all of these word copying tasks, gaze lifts could reflect reading abilities (e.g., grapheme to phoneme relations or whole-word knowledge) but also visual on-line processes (e.g., visual attention span). The second goal of our research was to assess whether gaze lift production during text copying also involves on visual attention span abilities.

In the current study, participants were normal reading children of grades 3 and 5. At this age the children are highly proficient on grapheme to phoneme correspondences but the orthographic lexicon and grapho-motor skills are still in progress. All participants copied and read the same text. We noted gaze-lifts during copying and measured eye-movements during reading. The VA span was estimated off-line with the letter report tasks. If the VA span is a visual mechanism involved in letter processing within strings, it should be a common component in both copying and reading processes. Furthermore, the VA span should 
specifically relate to the dimensions of the tasks that reflect visual processing, namely the number of rightward fixations and gaze lifts. According to this rationale, the children with smaller VA spans should produce gaze lifts more frequently during copying and make more rightward fixations during reading.

\section{Method}

\section{Participants}

The participants were 75 children from various social backgrounds recruited in a primary school of the Grenoble urban area. There were $343^{\text {rd }}$ graders (mean age $=8$ years 11 months , $\mathrm{SD}=5$ months) and $415^{\text {th }}$ graders (mean age $=11$ years 0 month, $\mathrm{SD}=7$ months). Their mean reading age was 9 years 4 months ( $\mathrm{SD}=17$ months) and 10 years 2 months $(\mathrm{SD}=22$ months), respectively as measured through the Alouette Reading Test (Lefavrais, 1965). All the children were native French speakers with normal or corrected to normal vision. Their average non-verbal IQ percentile was 59.6 (Raven, Court, \& Raven, 1998); $49.6(\mathrm{SD}=28.6$ ) in grade 3 and $68.0(\mathrm{SD}=28.2)$ in grade 5 (all ranges $=10-95, \mathrm{~F}(1,73)=7.79, \mathrm{p}<.01)$. Nine percent of the grade 3 participants and 15 percent of the grade 5 participants had repeated a grade. We decided not to exclude them from the analysis because our main goal was to examine the relationship between VA span, eye movements in reading and the copying task, and not the cognitive skills of children at a given age. However, age was systematically controlled for in all the analyses.

\section{Material and procedure}

The children had to read aloud and copy the same text. Half of the children read the text and then copied it, and the other half did the reverse order. Their VA span was estimated off-line 
with global and partial report tasks before or after the reading and copying tasks in a counterbalanced fashion.

\section{The copying task and gaze lift recording}

In the copying task, the text was presented on an A4 sheet. We read the title to the child: "Le monster poilu" (The hairy monster, written by H. Bichonnier, Gallimard Editor; see Appendix). The child started copying the text from the beginning of the first sentence. The text was written in Times New Roman, size 14 (7 lines, 100 words, 443 letters). The children had to copy it on the lined space presented below the text during three minutes. The experimenter told them to copy the text as accurately as possible, without omitting any words. While the child copied the text, the experimenter followed the child's eye movements and noted every time his/her eyes went back to the original text. Although this procedure does not provide information on the exact location of the gaze lift nor on the timing of ocular fixations, it presents the advantage of being very simple. At the end of the task, we counted the number of letters the child copied correctly. This refers to the total number of letters written minus the letters added or substituted in comparison with the model (these errors represented less than $1 \%$ of the written letters for both grades). Then we calculated the number of letters copied per gaze lift.

\section{The reading task and eye movement recordings}

In the reading condition, the participants had to read aloud the same text from the computer screen. Their reading performance was tape-recorded so we could measure reading speed. For practical reasons, the text was amputated by the last sentence and displayed in two paragraphs of four lines each, made up of 39 and 49 words respectively (see Appendix). Each paragraph was displayed successively on the screen without time limit. The text was $31^{\circ}$ wide 
and $6.8^{\circ}$ high. Each letter subtended 0.6 degree of visual angle at a distance of $60 \mathrm{~cm}$. The distance between the lines was $1.5^{\circ}$. A drift correction was performed before each paragraph. The target used to perform the drift correction was located at the beginning of each paragraph, where the first word subsequently appeared.

The eye movements were recorded from both eyes every $4 \mathrm{~ms}$ using a video-based EYELINK I system (SR Research) in a natural binocular viewing situation. The analyses concern the data of the right eye. The displays were generated using an ELSA GLADIAC MX card and a DELL P1110 monitor. A calibration procedure was carried out before the task, requiring the participants to track the position of nine fixation points extending throughout the visual field where the text was presented. The children's head was kept up at the level of the temples so that the lower jaw remained free to do the movements required for articulation. Thus, the head was mostly still and the system compensated for small head movements, if any. The six return sweeps, the corrective fixations following these return sweeps, as well as the fixations shorter than $100 \mathrm{~ms}$ (5\% of the total number of fixations) were removed from each recording file. We measured the total number of fixations higher than $100 \mathrm{~ms}$ (two fixations on a given word were considered as two different fixations), mean fixation duration, proportion of regressive saccades and the mean amplitude of forward and regressive saccades on the three first lines of both paragraphs of the text ( 83 words), to avoid interference due to the end of recording.

\section{The letter report tasks and visual attention span assessment}

The participants were assessed using two tasks of global and partial letter-report designed to estimate the number of distinct letters that could be extracted in parallel from a brief visual display (taken from Bosse et al., 2007). The stimuli were random 5-letter strings (e.g., R H S D M) that were generated with 10 consonants $(B, P, T, F, L, M, D, S, R, H)$. The letters could 
not be repeated within a string. They were presented in uppercase (Geneva, $0.8^{\circ}$ high) in black on a white background. The distance between adjacent letters was of $0.57^{\circ}$ in order to avoid lateral masking. The whole line subtended an angle of approximately $5.4^{\circ}$.

Each trial began with the presentation of a central fixation point for $1000 \mathrm{~ms}$ followed by a blank screen for $50 \mathrm{~ms}$. A letter string was then presented at the centre of the display for $200 \mathrm{~ms}$, a duration which corresponds to the mean duration of fixations in reading. It is long enough for an extended glimpse, but too short for a useful eye movement. In the global report task, the participants' task was to report verbally all the letters immediately after they disappeared. We noted the number of letters reported correctly (identity not location) in each trial $(\operatorname{Max}=5)$. There were 20 trials.

In the partial report task, a probe -a vertical bar- indicating the letter to be reported was presented for $50 \mathrm{~ms}, 1.1^{\circ}$ below the target letter, at the offset of the letter string. Each letter was used as target once in each position. The child had to report the letter above the probe. We noted whether the child reported the correct response for each trial. There were 50 trials.

In both tasks, the experimenter pressed a button to start the following trial after the participant's oral response. Eye movements were not monitored, but the requirement of central fixation was strongly emphasized and repeated at regular intervals during the experiment. The VA span was estimated as the mean of the results in the global and partial report tasks $(\operatorname{Max}=5)$.

Results

Table 1 presents mean reading speed and eye movement measures during reading, results for gaze lift data in the copying task and VA span estimation. We ran ANOVAs for reading, copying and VA span estimation tasks, with grade level as between-participants factor. 
Table 1. Mean reading speed and oculomotor measures during reading, results from gaze lift data in the copying task and VA span estimation. Standard deviations are in parentheses.

Grade 3

Grade 5

\begin{tabular}{|c|c|c|c|}
\hline & Reading speed (Wpm) & $107(27)$ & $138(33)^{* *}$ \\
\hline & Number of fixations & $164(39)$ & $138(48)^{*}$ \\
\hline \multirow[t]{3}{*}{ Reading task } & Fixations duration (ms) & $256(49)$ & $230(38)^{*}$ \\
\hline & Number of rightward saccades & $122(25)$ & $100(26)^{* *}$ \\
\hline & Regressive saccades (\%) & $28(6)$ & $28(7)$ \\
\hline
\end{tabular}

Copying Task Number of written letters

$148(32) \quad 204(43) * * *$

Total number of GL

$34(9.4)$

$35(14.8)$

Number of written letters per GL

$4.52(1.77)$

$5.91(2.53)^{* *}$

VA Span

Global report score $(\operatorname{Max}=5)$
Partial report score $(\operatorname{Max}=5)$
Number of letter reported $(\operatorname{Max}=5)$

$4.28(.45)$

$4.30(.43)$

$4.44(.46)$

$4.46(.33)$

$4.36(.41)$

$4.38(.32)$

Note: $*=\mathrm{p}<.05, * *=\mathrm{p}<.01$ and $* * *=\mathrm{p}<.001$.

The analysis revealed that fifth graders read faster than third graders $(\mathrm{F}(1,73)=19.37$; $\mathrm{p}<0.01)$. Concerning the eye movements during reading of the three first lines of both paragraphs of the text (see the Appendix), the children in Grade 3 made more fixations than in Grade $5(\mathrm{~F}(1,73)=6.17 ; \mathrm{p}<.05)$. Furthermore, fixation duration was longer in Grade 3 than in 
Grade $\left.5\left(\mathrm{~F}_{1,73}\right)=6.91, \mathrm{p}<.05\right)$. We also observed more rightward saccades in Grade 3 than in Grade $5(\mathrm{~F}(1,73)=12.69, \mathrm{p}<.01)$. There were no differences in percentage of regressive saccades between the groups, $\mathrm{F}<1$.

In the copying task, the children in Grade 3 copied less words $(F(1,73)=6.24, p<.001)$ and less letters per GL $(\mathrm{F}(1,73)=7.23, \mathrm{p}<.01)$ than the children in Grade 5. However, the total amount of gaze lift was not significantly different between grades $(F(1,73)=1.49$, n.s. $)$. Table 1 shows that Grade 3 children can copy 4.5 letters per GL on average whereas in Grade 5 children can copy almost 6 (5.91). The mean VA span was large for both grades and no VA score improved significantly from Grade 3 to Grade 5 (all $\mathrm{F}(1,73)<1)$.

We conducted correlation analyses to examine the relationship between the copying task, the text reading task and the VA span, at each Grade level. Table 2 presents the results of the correlation analyses.

Table 2. Partial correlations controlled for age, between reading speed, the oculo-motor measures during reading, the copying task and VA span.

VA Span

$\mathrm{Nb}$ Letters/Gaze Lift

Grade $3 \quad$ Grade $5 \quad$ Grade $3 \quad$ Grade 5

\begin{tabular}{lcccc}
\hline VA span & - & - & $.40^{*}$ & $.42^{* *}$ \\
\hline Reading speed $(\mathrm{Wpm})$ & $.59 * * *$ & $.38^{*}$ & $.38^{*}$ & $.33^{*}$ \\
Number of rightward saccades & $-.41^{*}$ & $-.32 *$ & $-.35^{*}$ & -.26 \\
$\%$ of regressive saccades & -.13 & -.26 & -.06 & -.16 \\
Fixation duration & $-.41^{*}$ & -.09 & -.19 & -.19 \\
\hline
\end{tabular}

Note $: *=\mathrm{p}<.05 ; * *=\mathrm{p}<.01 ; * * *=\mathrm{p}<.001$ 
The analysis revealed that VA span abilities correlated with reading speed at all grades. The correlation was weaker for $5^{\text {th }}$ graders. VA span correlated negatively and weakly with the number of rightward saccades during text reading at each grade but did not relate to the rate of regressive saccades. This means that the children with a larger VA span made less rightward saccades and thus produced saccades of larger amplitude towards the right. The relationship with fixation duration was modulated by grade level. A significant but weak relationship was observed in $3^{\text {rd }}$ grade but not in $5^{\text {th }}$ grade.

For both groups we observed that the number of copied letters per GL was significantly and positively correlated with both reading speed and VA span size. This reveals that the children who copied more letters per GL were those who read faster and who had high VA span scores. Correlations further showed that in $3^{\text {rd }}$ grade, the children who needed to produce more rightward saccades during text reading were the ones that copied less letters per gaze lift. This pattern of results was not significant for the 5th graders. The other correlations between the reading and copying tasks were not significant.

During the copying task, participants read the words they had to copy. Then, the number of letters copied per gaze lift could depend essentially on reading abilities and one could think that the correlation between VA span and the copying task is entirely mediated by reading skills. We conducted a regression analysis (Table 3) to examine whether the number of letters copied per gaze lift was related to VA span even when reading was controlled for. 
Table 3. Hierarchical regression analysis, predicting the number of letters copied per gaze lift during the copying task from control variables (grade, age and IQ), reading variables (reading speed and number of rightward saccades) and VA span

$\mathrm{Nb}$ Letters/Gaze Lift

$\begin{array}{llll}\mathrm{R} & \Delta \mathrm{R}^{2} & \mathrm{t}\end{array}$

Control variables

Step 1 Grade

.30

$.09 * *$

.43

1.6

Step 2 Age

.38

$.05^{*}$

$-.28$

$-1.1$

Step 3 IQ

.41

.02

.03

.3

Reading variables

Step 4 Reading speed (Wpm)

.50

$.08 * *$

.15

.8

Step 5 Number of rightward saccades

.50

.00

$-.08$

$-.4$

Step 6 VA span

.55

$.06^{*}$

.28

$2.4^{*}$

Note : the $\beta$ and $\mathrm{t}$ values are those obtained at the final step of the analysis; $*=\mathrm{p}<.05, * *=\mathrm{p}$

$<.01$

The regression analysis is globally significant $(\mathrm{F}(5,69)=6.07, \mathrm{p}<.001)$ and the total amount of variance in copying performance explained by the whole variables was substantial (Total $\mathrm{R}^{2}$ $=.30$ ). School grade, chronological age and non verbal IQ explained together $16 \%$ of the variance. The negative (but not significant) beta values of age effect reflect the fact that $9 \%$ of the grade 3 participants and $15 \%$ of the grade 5 participants had repeated a grade. So, it is 
likely that, in each grade, the older children were those who had the lowest performance in scholar tasks such as reading and copying. After this control, the reading speed variable was significant ( $8 \%$ of explained variance). The number of rightward saccades did not explain a supplementary part of variance. Moreover, the unique contribution of VA span to copying performance was significant. When entered at the final step of the analysis, the VA span still explained $6 \%$ of the variance. This analysis showed that the relation between the copying task and VA span was not entirely mediated by reading abilities. It also suggests that word visual processing is not equivalent during reading and copying.

\section{Discussion}

The VA span is involved in the "extraction" of orthographic information during letterstring processing (Bosse et al., 2007). It refers to a visual processing mechanism that delineates the number of letters that can be processed simultaneously in a letter string and become available for subsequent high level processing. The present research examined whether the VA span is involved both in copying and reading skills. Eye movements were recorded during a text reading task to assess whether the VA span relates to the eye movement features that are specifically involved in visual processing, namely the number of rightward saccades. In the copying task the children had to copy the same text. We also expected the number of letters processed per gaze lift to be related to VA span size.

The first set of data confirmed previous results on reading skills, copying performance and VA span size. The results for the reading task are in agreement with previous developmental data on eye movement measures (Rayner, 1998). The number of rightward fixations and their duration decreases with age, whereas the percentage of regressive saccades remains stable. Also in line with previous findings, the older children copied more letters per GL than the younger ones (Kandel \& Valdois, 2006a, 2006b). 
The second set of analyses examined the link between VA span abilities, eye movements during reading and gaze lifts during copying. The number of rightward fixations is known to be affected by the amount of visual information available at each glance (Rayner $\&$ Pollatsek, 1981). The other measures as fixation duration and regression rate are primarily determined by higher order linguistic factors, such as word frequency or predictability (Frisson, Rayner, \& Pickering, 2005; Hyönä \& Olson, 1995; Liversedge, Rayner, White, Vergilino-Perez, Findlay, \& Kentridge, 2004). In line with our expectations, the VA span was correlated at each grade with the number of rightward fixations. This finding comforts previous results showing a similar relationship between VA span abilities and the number of rightward fixations in dyslexics (Prado et al., 2007). The overall findings are in line with the idea that VA span abilities relate to the number of letters analysed simultaneously during reading. VA span abilities and fixation duration only correlated in grade 3 . Future studies are required to assess the reliability of this unexpected relationship.

We also expected that the VA span would be linked to information extraction during copying. The significant correlation between the letter report tasks and the number of letters copied per GL in both grades supported this idea. The children who identified more letters in the consonant string in the letter report task were the ones who processed more letters at each gaze lift during the text copying task. The correlations between the copying task and reading skills were also significant for both grades (reading speed for $5^{\text {th }}$ graders, reading speed and number of rightward saccades for $3^{\text {rd }}$ graders) and confirm that the copying task also relies on reading skills. Since the VA span correlated with both reading and copying performance, it could be argued that the relationship between VA span and copying is entirely mediated by reading processes. To test this hypothesis, a regression analysis was conducted on all participants, with the number of letters copied per GL as the dependent variable. The analysis included six factors: grade, age, IQ, reading speed, number of rightward fixations and VA 
span. The result indicated that, after control of the variance explained by grade, age and reading performance, VA span contributed independently to copying performance. This finding suggests that the number of letters processed per gaze lift during a copying task not only depends on reading skills (grapheme to phoneme relation knowledge or whole-word knowledge) but also on simultaneous visual on-line processes. Thus, the copying task involves a level of visual analysis that is not influenced by the linguistic characteristics of the text to be processed but relies on the visual attention mechanisms -or VA span- required for the extraction of orthographic information from the printed text.

Although the letter report tasks were designed to assess the VA span, its purely visual nature is still under debate (Lobier et al., 2012; Ziegler et al., 2010). As mentioned above, the influence of top-down processes in the task is unlikely and they do not involve any of the phonological mechanisms of reading (as grapheme-phoneme correspondences or phonological blending). Furthermore, Lassus-Sangosse et al. (2008) showed that the letter report task is not sensitive to verbal short-term memory. In their experiment the same consonants as in our letter report tasks were displayed successively, one at a time, on the computer screen. The participants had to report their names. The results showed that dyslexic children with a small VA span performed as the matched controls. Other studies provided evidence indicating that articulatory suppression affected the performance in the global report task very slighly (Valdois et al., 2012b). Recent dyslexic data also revealed that the concept of VA span extends to non-verbal material and non-verbal tasks (Lobier et al., 2012). VA span abilities thus refer to visual processing. The correlations between letter report tasks and rightward fixations in reading and GL in copying comfort the idea that the VA span is a visual parallel processing mechanism. It operates very early and concerns all the tasks requiring the processing of an orthographic input.

These findings provide new insights on the cognitive processes involved in copying. 
The copying task obviously involves reading skills but can be performed without high cognitive demands since even new orthographic sequences (as pseudo-words or letter sequences that cannot be read) can be copied accurately. The present study shows that performance on this task depends on the children's visual attention skills and their ability to process visually several letters simultaneously. As a consequence, copying performance relies not only on high level processes but also on the visual attention mechanisms involved in the extraction of orthographic information. 


\section{References}

Ans, B., Carbonnel, S., \& Valdois, S. (1998). A connectionist multi-trace memory model of polysyllabic word reading. Psychological Review, 105, 678-723.

Bosse, M.-L., Tainturier, M.-J., \& Valdois, S. (2007). Developmental dyslexia : the Visual Attention Span hypothesis. Cognition, 104, 198-230.

Bosse, M.L., \& Valdois, S. (2009). Influence of the visual attention span on child reading performance: a cross sectional study.Journal of Research in Reading, 32,2, 230-253.

Frisson, S., Rayner, K., \& Pickering, MJ. (2005). Effects of contextual predictability andtransitional probability on eye movements during reading. Journal of ExperimentalPsychology: Learning, Memory and Cognition. 31(5), 862-877.

Humblot, L., Fayol, M., \& Lonchamp, K. (1994). La copie de mots en CP et CE1. Repères, 9, 47-60.

Hyönä, J., \& Olson, R.K. (1995). Eye fixation patterns among dyslexic and normal readers: Effects of word length and word frequency. Journal of Experimental Psychology: Learning, Memory and Cognition, 21(6), 1430-1440.

Kandel, S., \& Valdois, S.(2006a). Syllables as functional units in a copyingtask. Language and Cognitive Processes, 21(4), 432-452.

Kandel, S., \& Valdois, S. (2006b). French and Spanish-speaking children use different visual and motor units during spelling acquisition. Language and Cognitive Processes, 21(5), $531-561$

Lambert, E., Alamargot, D., Larocque, D., \& Caporossi, G. (2011). Dynamics of the spelling process during a copy task: effects of regularity and frequency. Canadian Journal of Experimental Psychology, 65, 141-150. 
Lassus-Sangosse, D., N'Guyen-Morel, M. A., \& Valdois, S. (2008). Sequential orparallel simultaneous visual processing deficit in developmental dyslexia? Vision Research, 48, 979-988.

Lefavrais, P. (1965). Test de l'Alouette. Paris: Editions du centre de psychologie appliquée.

Liversedge, SP., Rayner, K., White, SJ., Vergilino-Perez, D., Findlay, JM., \& Kentridge, RW. (2004). Eye movements when reading disappearing text: is there a gap effect inreading? Vision Research, 44(10):1013-1024.

Lobier, M., Zoubrinetzky, R., \& Valdois, S. (2012). The VA span deficit in developmental dyslexia is visual and not verbal. Cortex, 48, 768-773.

Prado, C., Dubois, M., \& Valdois, S. (2007). The eye movements of dyslexic children during reading and visual search: Impact of the visual attention span. Vision Research, 47, 25212530.

Raven, J. C., Court, J. H., \& Raven, J. (1998). Progressive matrices standard (PM38). Paris: EAP.

Rayner, K. (1998). Eye movements in reading and information processing: 20 years of research. Psychological Bulletin, 124(3), 372-422.

Rayner, K., \& Pollatsek, A. (1981). Eye movement control during reading: Evidence for direct control. Quaterly Journal of Experimental Psychology, 33A, 351-373.

Rieben, L., \& Saada-Robert, M. (1991). Developmental patterns and individual differences in the word-search strategies of beginning readers. Learning and Instruction, 1, 67-87.

Valdois, S., Bosse, M.-L., \& Tainturier, M.-J. (2004). The cognitive deficits responsible for developmental dyslexia: Review of evidence for a selective visual attention disorder. Dyslexia, 10, 1-25. 
Valdois, S., Lassus-Sangosse, D. \& Lobier, M. (2012a). Impaired Letter-String Processing in Developmental Dyslexia: What Visual-to-Phonology Code Mapping Disorder? Dyslexia, 18,(2), 77-93.

Valdois, S., Lassus-Sangosse, D. \& Lobier, M. (2012b). The visual attention span deficit as a purely visual attention disorder in developmental dyslexia. In J. Stein \& Z. Kapoula (Ed.), Visual aspects of Dyslexia. Oxford University Press.

Ziegler, J. C., Pech-Georgel, C., Dufau, S., \& Grainger, J. (2010). Rapid processing of letters, digits and symbols: what purely visual-attentional deficit in developmental dyslexia? Developmental Science, 13(4), F8-F14. 
Appendix. The text used in the copying task. The two paragraphs displayed separately during the reading condition are indicated by the brackets. Words of the three first lines of each paragraph, on which reading measures were made, are in bold.

[Le monstre poilu vivait dans une caverne humide et grise, au milieu d'une sombre forêt. Il avait une grosse tête posée directement sur deux pieds ridicules, ce qui l'empêchait de courir. Il ne pouvait donc pas quitter sa caverne.] [Le monstre avait des poils partout : au nez, aux pieds, au dos, aux dents, aux yeux et ailleurs. Tous les jours, il se postait sur le seuil de sa caverne et disait, avec des ricanements sinistres : « Le premier qui passe, je le mange ». Mais il ne passait jamais personne,] car dans cette région la forêt était bien trop noire et profonde. 